\title{
HISTORY OF ENDOCRINOLOGY
}

\section{Siyambalapitiya $\mathbf{S}^{1}$}

${ }^{1}$ Diabetes and Endocrine unit, North Colombo Teaching Hospital, Ragama.

Clinical endocrinology is a branch of Medicine that deals with the endocrine glands, the secreted hormones and their metabolic effects. Hormones act on almost every organ and cell type in the body and there are disorders that are entirely or largely related abnormalities of hormone production. Type I diabetes and hypothyroidism are such examples that entirely related to abnormalities of hormones. However, there are so many other disorders such as osteoporosis and infertility, which are related to hormone dysfunction.

History of endocrinology and study of hormone function dates back to $400 \mathrm{BC}$ when Hippocrates and Galen introduced the concept of Humoral Hypothesis where they describe as the four humors (body fluids) held the secret to health and any undue preponderance of any one humor would result in characteristic pattern of disease.

Aristotle noted that there were changes in physical and behavioral aspects after castration on roosters. It was also noted that pre-pubertal castration in humans led to short men with long arms without facial hair and pubertal change in voice. These eunuchs were used to guard the doors of the queens and noble women in ancient times. During $17^{\text {th }}$ and $18^{\text {th }}$ century, it was common practice in Europe and in Asia where young boys with singing voices were castrated in order to prevent the pubertal changes in voice and use them as choir boys.

Although there was evidence to suggest that internal substances that are released by some organs can have generalized effects, nobody really understood the mechanism as to how it happens till late 1600's. The first recorded researchers who were experimenting with the circulation and the hormones were William Harvey (1628), John Hunter (late 1600's) and Bordeaux (1775). Arnold Berthold conducted the first experiment showing constancy of the Internal Environment. Claude Bernard (in 1872) found that the cells and tissues need to communicate for coordination of physical activities and this is regulated by the internal secretions by the ductless glands. The term "Endocrine" was used by Claude Bernard to describe these internal secretions and hence the birth of the field of Endocrinology in modern clinical medicine.

After $19^{\text {th }}$ century, there has been a dramatic expansion with significant advancements in this field of medicine. In 1889, a French physician, Charles Brown-Sequard did the first experiment of hormone replacement therapy by injecting dog, guinea pig and rabbit testicular extracts by by himself. Later, the demonstration of blood glucose lowering property of pancreatic dog extract by Von Mering and Menkoski led to the discovery of insulin during the early part of $20^{\text {th }}$ century. However, the first described hormone (1902) was a result of efforts by Sir William Bayliss (1860-1924) and Ernest Starling (18661927). In response to the delivery of acidic chyme from the stomach to the intestine, endocrine cells of the duodenum release secretin (an internal secretion) into the bloodstream, which is responsible for the stimulation of exocrine pancreas to secrete bicarbonate to neutralize acid coming from the stomach. Secretin was the first hormone to be identified and many more were found later. Although we have a substantial knowledge regarding these molecules, a lot of research is being carried out to understand more about these substances. The better we know about these hormones, the better understand the related pathological problems and hence the treatment for the related disorders.

Today, Endocrinology has become a very specialized field of medicine where we deal with clinical disorders of endocrine system and their complex pathophysiological and management problems. Currently, vast number of clinicians and scientist are involved with the discovery and assaying the structure and functions of various hormones and finding ways to treat these complex clinical problems. On the other hand, the field of endocrinology, in conjunction with genetic engineering, has taken a leading role in the farming industry in order to optimize the yield from the crops and animal produce. It is a rapidly evolving field of medicine, which has contributed immensely to wellbeing of the human beings in many ways.

\section{SOURCES}

1. Temkin O. Greek Medicine as Science and Craft. ISIS 1953; 44(3): 213-225.

2. Haris DF. The Influence of Greece on Science and Medicine. The scientific Monthly 1916; 3(1): 51-65.

3. Langdon-Brown W. The history of Endocrinology. Proceedings of the Royal Society of Medicine 1940; 34:25-30.

4. Rollestone R. The History of Endocrinology. British Medical Journal 1937;1(3984): 1033-1036. 